\title{
Health sciences students' contribution to human resources for health strategy: A rural health careers day for grade 12 learners in the North West Province of South Africa
}

N O Mapukata, ${ }^{1}$ MSc (Health Care Management), MSc (Med); I D Couper, ${ }^{2}$ MB BCh, MFamMed, FCFP (SA); A R Dreyer, ${ }^{1}$ MPH; $\mathbf{M ~ M l a m b o , ~}{ }^{1} \mathrm{PhD}$

${ }^{1}$ Centre for Rural Health, Faculty of Health Sciences, University of the Witwatersrand, Johannesburg, South Africa

${ }^{2}$ Ukwanda Centre for Rural Health, Faculty of Medicine and Health Sciences, Stellenbosch University, Cape Town, South Africa

Corresponding author: N Mapukata (ntsiki.mapukata@wits.ac.za)

\section{Context and setting}

South Africa (SA) has made significant strides towards ensuring that the profile of learners admitted to its eight medical schools reflects the demographics of the country. Yet, despite these efforts, SA is still plagued by human-resource challenges within the health sector, with the majority of healthcare professionals preferring to work in urban areas. ${ }^{[1]}$ The Wits Initiative for Rural Health Education (WIRHE) scholarship is one of the programmes that was established by the Centre for Rural Health (CRH) as a response to the workforce challenges facing rural areas of SA. This programme provides opportunities to students from previously disadvantaged rural communities to register for professional degrees offered by the faculties of health sciences at any of the three medical schools in Gauteng Province: the universities of the Witwatersrand, Pretoria and Sefako Makgatho (previously Medunsa) ${ }^{[2]}$ As such, the launching of the first Rural Careers Day in the North West Province was informed by the experiences of managing the WIRHE scholarship programme, which highlighted the challenges faced by students from rural communities who try to gain access to institutions of higher education. ${ }^{[3]}$ This report describes the Wits CRH experience of organising a student-led rural health careers day as a pilot project, and an evaluation thereof based on the experiences of the participating students and learners.

\section{Why the idea was necessary}

We recognised the effectiveness of student-learner mentorship based on previous experiences where Wits medical students were required to provide input about careers in rural high schools in the Bojanala District of the North West Province. Health sciences students are seldom given the opportunity to engage with high school learners in a structured programme. The hosting of a careers day in a rural district was initiated to create and strengthen an awareness of and enthusiasm for careers in the health sciences among grade 12 rural high school learners.

\section{What was done}

Twenty-four senior health sciences students volunteered to facilitate a series of mini-workshops on career options, funding opportunities and healthpromotion topics for learners from 85 high schools in Ngaka Modiri Molema District in the North West Province. A total of 224 top-five rural learners completed a self-administered questionnaire once they had completed their rotation through all the stations to evaluate their views of the day.

\section{Results and impact}

Feedback from the high school learners demonstrated that they became better informed about career options in the health sciences fields (93\%).
Most learners indicated that they would recommend the day's activities to their peers $(97 \%)$. The highest career preference score was for medicine (94\%) (Fig. 1). Of the health-promotion stations, substance abuse received the highest ranking (80\%) compared with the other topics, including HIV/ AIDS, sexually transmitted infections and teenage pregnancy. Learners perceived the applications and funding station to be 'informative' ( $80 \%)$, although they indicated a need for additional information on funding. By engaging learners on health-promotion topics related to their sexual health and life choices, they may have benefited from the exposure and may even develop an appreciation for primary healthcare-intervention strategies and the role of universities at the community level. Through designing and implementing programmes that link students to communities, universities have the potential to contribute positively to the realisation of healthcare goals in rural communities.

Acknowledgements. We would like to extend our appreciation to the Wits students who joined us as volunteers, many of whom have completed their studies, and the Ngaka Modiri Molema District for its role and contribution on the Rural Careers Day.

Author contributions. NM: project director and prepared the initial draft; IDC, ARD, MM: contributed to the project design, participated in the review and contributed to the final draft.

Funding. Partial funding was received from the CSI Division: Toyota South Africa.

Conflicts of interest. None.

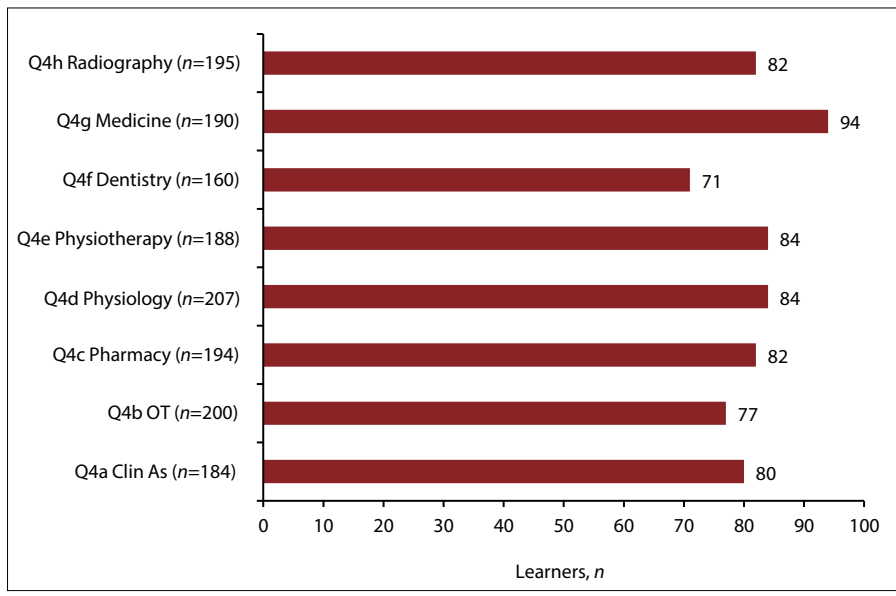

Fig. 1. Learners' rating of the relevance of each career choice station. $(Q=$ question; OT = occupational therapy; Clin As = clinical associate.) 


\section{Short Communication}

Khan T, Thomas LS, Naidoo S. Analysing post-apartheid gender and racial transformation in medical education in a South African province. Global Health Action 2013;(6)10. https://doi.org/10.3402/gha.v6i0.19810

2. Ross AJ, Couper ID. Rural scholarship schemes: A solution to the human resource crisis in rural district hospitals. S Afr Fam Pract 2004;46(1):5. https://doi.org/10.1080/20786204.2004.10873025

3. Sondzaba N, Couper I. WIRHE scholarship - a case study of recruitment, support and retention of a rural workforce in North West. In: Conference Proceedings: Celebrating Innovative Health Management Conference, Cape Town, 20 - 30 June 2011. https://uct-heu.s3.amazonaws.com/wp-content/../2011/..//Health-Managementreport_final.p (accessed 17 August 2017).

Accepted 11 January 2017

Afr J Health Professions Educ 2017;9(3):92-93. DOI:10.7196/AJHPE.2017.v9i3.856 